\title{
O SUPREMO TRIBUNAL FEDERAL NO PROCESSO DE TRANSIÇÃO DEMOCRÁTICA: UMAANÁLISE DE CONTEÚDO DOS JORNAIS FOLHA DE S. PAULO E O ESTADO DE S. PAULO
}

\author{
Fabiana Luci de Oliveira
}

\section{RESUMO}

O artigo discute a presença do Supremo Tribunal Federal (STF) no cenário público nacional no processo de abertura política e de consolidação da democracia (entre os anos de 1979 a 1999), buscando entender as relações do Tribunal com o Estado, a sociedade e a política, a partir da maneira como o STF foi percebido por alguns veículos formadores da opinião pública, utilizando como parâmetro dois jornais de São Paulo: Folha de S. Paulo $e \mathrm{O}$ Estado de S. Paulo. Os jornais serviram como um "termômetro" da inserção e atuação desse ator no cenário público nacional. A conclusão a que se pôde chegar foi a de que o Tribunal buscou transformar a imagem de que desfrutava na opinião pública, passando de uma situação em que era identificado como alheio à realidade e às necessidades do país, à imagem de instituição de importância central para o desenvolvimento da nação.

PALAVRAS-CHAVE: Supremo Tribunal Federal; profissão; política; Folha de S. Paulo; O Estado de S. Paulo; opinião pública.

\section{INTRODUÇÃO}

O papel que o poder Judiciário - mais especificamente que o Supremo Tribunal Federal (STF) - vem desempenhando no cenário político brasileiro tem sido muito discutido a partir do fenômeno da judicialização da política. O fenômeno, segundo Vallinder, significa "(1) a expansão da área de atuação das cortes judiciais ou dos juízes às expensas dos políticos e/ou administradores, isto é, a transferência de direitos de decisão da legislatura, do gabinete ou da administração pública às cortes judiciais, ou, ao menos, (2) a propagação dos métodos judiciais de decisão para fora das cortes de direito propriamente ditas" (Vallinder apud CASTRO, 1997, p. 154). Esse conceito denota a expansão do poder das cortes judiciais, atribuído em grande parte devido à possibilidade de essa instância julgar a constitucionalidade das leis.

Werneck Vianna e seus colaboradores (1999) também falam em judicialização da política como a invasão da lógica racional-legal no ordenamento da política e acrescentam ao debate o que designam por judicialização das relações sociais, ou seja, a invasão da lógica racional-legal no ordenamento das relações sociais. Esses dois fenômenos colocariam o poder Judiciário na posição de nova arena de disputa e de conflitos no cenário público brasileiro.

A interpretação do papel desempenhado pelo STF no campo da política não é consensual, principalmente no que se refere à participação do Tribunal no processo de transição do regime militar para o regime democrático. Grande parte da bibliografia que trata do tema, especialmente no olhar da Ciência Política, entende que o STF esteve ausente nesse processo de transição, ou então que sua presença deu-se de maneira submissa, não dispondo o Tribunal de força política ou abstendose de atuar politicamente. Nessa perspectiva, tal situação modificar-se-ia a partir da Constituição Federal de 1988, que, alterando a jurisdição do STF e ampliando seus poderes, colocou-o na posição de uma poderosa arena de decisão de conflitos. Com as diversas modificações que essa Constituição trouxe, o STF foi alçado ao centro do debate político e a discussão passou a ser a da extensão dos seus poderes. A partir de 1988 entende-se que o STF desempenha um poder

Rev. Sociol. Polít., Curitiba, 22, p. 101-118, jun. 2004

101 
político de fato e o olhar da Ciência Política voltouse, então, à discussão das conseqüências da atuação do poder Judiciário para a criação e a sustentação da democracia, debatendo os fenômenos da "judicialização da política" (extensão da lógica racional-legal no ordenamento da política) e da "politização da justiça" (extensão da lógica político-partidária ao processo de decisão judicial).

Essa interpretação de ausência ou submissão é baseada nos argumentos da limitação de competência do Tribunal, que não disporia de mecanismos eficientes para atuar, e no da falta de vontade política dos ministros que o compunham, que seriam subservientes ao governo (VALE, 1976; VIEIRA, 1993; WERNECK VIANNA et alii, 1999). Essa é a interpretação dominante, mas há outras que entendem que o STF esteve presente ativamente no processo de transição, não tendo sido um ator marginal (ROSA, 1985; OSIEL, 1995).

Esse é o debate presente na Ciência Política debate com poucas vozes dissonantes - e que serviu como ponto de partida para a presente pesquisa. Nossa proposta é dele participar, com um olhar diferenciado, sob a ótica da Sociologia das Profissões, verificando a possibilidade de pensar os ministros do STF a partir do mundo profissional do Direito que, entre outras características, requer a necessidade do diploma de Bacharel em Direito para o exercício da profissão e pressupõe o conhecimento técnico e a autonomia profissional para a realização de diagnósticos baseados no saber profissional, assim como a ideologia de prestação de um serviço independente e de qualidade à sociedade (BONELLI, 2002).

\section{O STF NO PROCESSO DE (RE)DEMOCRA- TIZAÇÃO E CONSOLIDAÇÃO DA DEMO- CRACIA NO BRASIL}

O objetivo desta seção é discutir a presença do STF no cenário público nacional no momento de abertura política e de consolidação da democracia (compreendendo os anos de 1979 a 1999), entendendo as relações entre o Tribunal, o Estado, a sociedade e a política nesse período, a partir da maneira como o STF foi percebido por alguns setores formadores da opinião pública, utilizando como parâmetro dois jornais de São Paulo: Folha de S. Paulo (FSP) e O Estado de S. Paulo (OESP).

Um aspecto levado em consideração é a diferença na postura ideológica adotada pelos dois jornais: o Estado é tido como um jornal mais conservador enquanto a Folha tende a ser considerada mais "liberal" (CAPELATO \& PRADO, 1980; AQUINO, 1999). Note-se que não se trata de um estudo sobre os meios de comunicação, mas sim de um estudo que se utiliza deles como fonte de dados, como um indício da tendência da formação da opinião pública em relação ao objeto considerado. $\mathrm{O}$ que se quer compreender é em que medida os jornais enfocados discutiram a atuação da instituição STF no processo de abertura e tentativa de (re)democratização da sociedade brasileira, e como eles perceberam e "publicizaram" essa atuação. Claro que esse "entendimento" está diretamente relacionado à maneira por que os ministros do STF procuraram inserir-se nos meios de comunicação e manifestar-se por meio deles.

Apesar do possível viés quando se utiliza a mídia como fonte de informações, é notório que ela constituiu um rico instrumento de pesquisa. Como afirma Garapon, "A mídia constitui mais do que um contrapoder e até mesmo um poder. Seu registro é o da autoridade compreendida como o poder de representar a realidade. [...] Como toda ideologia ela também tem a função de dissimular. A mídia ainda mascara a origem do seu poder. Imaginar uma sociedade totalmente transparente, um mundo que seria governado sem instituições, é simplesmente uma utopia. [...] A mídia constitui uma autoridade bem real, porém desconcertante, uma vez que é inconsistente, inconstante e inconseqüente, o oposto de uma instituição referenciada e bem situada, estável e operante" (GARAPON, 1999, p. 92-93).

Prosseguindo em suas considerações sobre o relacionamento entre poder Judiciário e os meios de comunicação, o autor comenta como alguns juízes utilizam-se da mídia estrategicamente, para lutar contra o encerramento de algum processo importante, ou então para defenderemse de críticas feitas ao poder Judiciário, ou mesmo para uma aproximação entre justiça e população, pois a mídia fornece um acesso direto à opinião pública-mas questiona se deveria ser esse o papel de um juiz, o de adotar um comportamento estratégico. Aqui não foram discutidas questões da implicação do relacionamento do STF com a mídia. Como explicitado, ela serviu apenas como um "termômetro" da inserção e atuação desse ator no cenário público nacional no período considerado. A bibliografia que trata do período 
concedeu pouca atenção ao tema; segundo Vieira, "O período da transição, sem as amarras dos AIs [atos institucionais] tem recebido pouca atenção por parte dos autores. É um período marcado por um grande silêncio por parte do Supremo, e dos tribunais em geral, em trabalhar em função da reconstrução do Estado de Direito e da democracia" (VIEIRA, 1993, p. 73). A maioria dos autores que tratou do relacionamento entre Judiciário e política no Brasil desse período discutiu, sobretudo, as limitações do papel do juiz na arena política.

Arantes e Kerche, ao analisarem o papel do poder Judiciário na transição do autoritarismo para a "nova democracia" no Brasil, caracterizando-a a partir do conceito de "poliarquia" de Robert Dahl, partem da hipótese de que as instituições judiciais brasileiras têm tido um importante papel no processo de abertura e "liberalização" do Estado nacional, entendendo liberalização como "redução das oportunidades de exercício despótico do poder político" (ARANTES \& KERCHE, 1999, p. 31).

Retomando o pensamento de Montesquieu e sua clássica teoria da separação dos poderes, relembram que a função precípua do poder Judiciário é cuidar da aplicação imparcial da lei, garantindo a igualdade jurídica e zelando pelo texto constitucional (idem, p. 32). Com isso o poder Judiciário é posicionado como guardião da Constituição e, como afirmam os autores, "[...] quando o Judiciário é erguido à condição de guardião da Constituição nos tempos modernos, sua tarefa é originalmente liberalizante e só posteriormente foi incorporada ao elenco dos valores também democráticos. Mais do que qualquer outra instituição política, o Judiciário encontra-se hoje na difícil posição de limitar as ações do Estado em contextos institucionais que se pretendem cada vez mais democráticos" (idem, p. 40).

Os autores concluem sua análise constatando que no Brasil o problema de o poder Judiciário exercer um contrapeso político é agravado pelo tipo de modelo de controle de constitucionalidade adotado no país (modelo híbrido, que mescla elementos do modelo difuso norte-americano com o modelo concentrado europeu-continental), colocando a questão da difícil governabilidade e da (in)efetividade do rule of law. "Em razão da Constituição de 1988, nosso sistema não é difuso porque contamos com o mecanismo da Ação
Direta de Inconstitucionalidade, patrocinada junto ao STF, com efeito erga omnes (contra todos). Desse ponto de vista o STF é quase uma Corte Constitucional. De outro lado, o sistema não é concentrado porque o STF não detém o monopólio da declaração de (in)constitucionalidade, dividindo essa competência com os juízes e tribunais inferiores de todo o país. Assim, quando o STF recebe recurso das instâncias inferiores em questões constitucionais, manifesta-se apenas como órgão de cúpula do Judiciário. Para completar o hibridismo desse sistema, entre nós as decisões do STF não vinculam decisões de órgãos judiciários inferiores, como ocorre nos Estados Unidos" (idem, p. 36).

Os autores apontam diversas tentativas de alterar a forma de inserção do poder Judiciário no sistema político nacional, entre elas a Medidas Provisória n. 173, proibindo a concessão de liminares em ações contrárias ao plano econômico do governo Collor, e a Medida Provisória n. 375, no governo Itamar Franco, que buscou constranger a concessão de liminares nos julgamentos envolvendo interesses da União. Citam também a Emenda Constitucional n. 3, de 1993, que criou a Ação Declaratória de Constitucionalidade, com efeito vinculante para as instâncias inferiores (idem, p. 38-39).

$\mathrm{Na}$ visão de Arantes e Kerche essas modificações não bastaram; eles vislumbram a realização de uma reforma que redefina o desenho institucional do poder Judiciário a partir de duas alterações centrais: 1) adoção do efeito vinculante das decisões do STF em matéria constitucional sobre as demais instâncias do poder Judiciário e 2) a adoção do incidente de constitucionalidade, trazendo ao STF processos envolvendo questões constitucionais relevantes, em curso nas instâncias inferiores. "Caso tais mudanças sejam efetivadas, o movimento de concentração do controle constitucional estará quase completo, com o STF sendo alçado à condição definitiva de Corte Constitucional. Dizemos ‘quase completo' porque essa corte ainda permanecerá na inconveniente posição de órgão de cúpula do poder Judiciário, com as responsabilidades ordinárias daí decorrentes" (idem, p. 39).

No presente trabalho a relação entre o poder Judiciário e a política é discutida a partir da ótica da Sociologia das Profissões, pensando o STF como um ator político diferenciado. A hipótese 
é de que esse Tribunal esteve presente como um importante ator desde o início do processo de abertura política, sendo que, com a alteração de suas atribuições constitucionais e a conseqüente ampliação de sua esfera de atuação e dos agentes legitimados a acionar tal poder, a partir da Constituição de 1988, ele desenvolveu um novo papel, de importância central no cenário político. Esse papel teria sido construído pelo Tribunal ao longo da República e estaria associado à identidade profissional dos ministros do STF. A inserção do Supremo na arena política seria, então, diferenciada pelo apego dos ministros a uma identidade fundada na ideologia profissional e no mérito do conhecimento técnico-jurídico, o que os distinguiria das outras elites políticas (OLIVEIRA, 2002).

III. O STF NOS JORNAIS FOLHA DE S. PAULO E $O$ ESTADO DE S. PAULO

Na realização desta pesquisa as notícias foram selecionadas pelo critério de referirem-se à instituição Supremo Tribunal Federal, fossem editoriais, artigos escritos por jornalistas, colaboradores de jornal ou pelos próprios ministros - incluindo-se também a seção de opinião dos leitores. A partir da análise do seu conteúdo foram construídas 23 categorias temáticas com que se buscou classificar cada uma das notícias.

Para a realização da análise da relação de associação estatística entre os dados, optou-se por recodificar as variáveis que apresentaram maior correlação entre si. Assim foram construídas sete temáticas: 1) interesses corporativos, referindose a questões financeiras e institucionais, incluindo a defesa de críticas ao STF; 2) crise/reforma do poder Judiciário, referindo-se à existência de uma crise e à necessidade de reforma do STF, com temas como a criação de uma Corte Constitucional, críticas ao processo de nomeação dos ministros, comparação do desempenho do STF com o de cortes de outros países e, para o período 19791988, crítica à prerrogativa do Procurador-Geral da República de propor a representação de inconstitucionalidade; 3) conflitos ideológicos, compreendendo as tensões referentes à posição doutrinária dos ministros; 4) papel político do STF, referindo-se ao papel político desempenhado pelo STF e aos processos de judicialização da política, politização da justiça e judicialização das relações sociais, incluindo no período de 1979-1988 a reivindicação dos ministros por uma participação mais ativa no processo de reforma; 5) papel jurídico tradicional, referindo-se ao desempenho do papel jurídico tradicional por parte do STF, enquanto instância máxima do poder Judiciário; 6) relações com os Poderes Executivo e Legislativo, referindose às relações de tensão ou apoio entre STF e poder Executivo ou poder Legislativo e 7) visão do STF, podendo ser positiva, relacionada à apresentação de uma imagem positiva do Tribunal na mídia, ou negativa, relacionada à presença de críticas.

A contabilização das categorias deu-se de acordo com o número de notícias em que apareceram. Assim, os percentuais de cada variável são referentes ao número total de notícias.

É importante atentar para algumas limitações impostas à coleta das notícias nos períodos de 1979-1993 (FSP) e 1979-1995 (OESP), em que o conteúdo dos jornais não está disponível de forma digital, tendo-se recorrido às pastas temáticas do Banco de Dados do Estado de São Paulo, encontrando-se apenas 215 notícias para a FSP e 58 para o OESP. Para os anos posteriores de cada periódico foram coletados, na internete, todos os artigos publicados referentes ao STF. O exame dessas notícias suscitou a seguinte periodização: 1979-1988 (período da abertura política), 1989-1993 (considerando o marco da primeira eleição direta depois do fim da ditadura e também o momento seguinte à nova Constituição) e 1994-1999 (governo Fernando Henrique Cardoso). Em decorrência das especificidades na coleta dos dados, a divisão para o OESP foi: 19791988, 1989-1995 e 1996-1999.

Embora tenha limitações na coleta de dados, a análise não deixa de trazer aspectos interessantes e de proporcionar uma idéia de como o STF era apresentado ao público (leitores) nos dois primeiros períodos considerados.

\section{III.1. Primeiro período (1979-1988)}

De maneira geral, as notícias publicadas nesse período deixaram transparecer um STF que buscava transformar sua imagem pública. Embora existam diferenças no enfoque dado ao Tribunal nos dois periódicos (o jornal OESP evidencia uma imagem tendencialmente mais positiva do STF), a imagem geral transmitida foi predominantemente negativa.

As notícias fazem referência às vantagens de que desfrutavam os ministros do Tribunal e ao fato de o STF abster-se de decidir questões 
relevantes para a vida política do país. A expressividade um pouco maior dessas notícias na FSP deveu-se, sobretudo, a uma tensão que se verificou entre alguns jornalistas dessa empresa e o Tribunal no ano de 1985, em decorrência da publicação de notícias que desagradaram aos ministros. "O voto do STF foi estritamente jurídico. Leu e entendeu a lei em vigor, sem discutila. Em conseqüência reconheceu legal a expulsão do Padre Vito. Assim procedendo, o Supremo brasileiro demonstrou, mais uma vez, a diferença entre qualquer alta corte em regime democrático e os tribunais superiores em autocracias, onde a supremacia do Poder Executivo não conhece limites. A vontade deste sempre se impõe" (ESPECTADOR SUPREMO, 1980).

Grande parte das notícias que indicam um posicionamento favorável ao Tribunal refere-se a um encontro convocado pelo então Presidente do STF, Ministro Xavier de Albuquerque, entre os ministros do Tribunal, proprietários de jornais e jornalistas, a fim de estabelecer um acordo, visando a aproximar o STF da opinião pública. Na notícia Revalorizar a Justiça, proposta do Supremo, publicada na FSP em 14.abr.1982, há uma declaração do Ministro Xavier de Albuquerque afirmando que a nação não podia mais suportar o distanciamento existente entre a opinião pública e o poder Judiciário, especialmente o próprio STF. Propunha a valorização do poder Judiciário, o que implicava esforços " [...] de resgatá-lo das páginas mais modestas da imprensa para as mais destacadas e condizentes com a sua importância institucional". $\mathrm{O}$ representante dos jornalistas referiu-se ao encontro como um "marco histórico e necessário: a aproximação do Supremo com a Nação e com o povo brasileiro".

Embora a imagem negativa predomine, percebe-se que o STF é retratado como uma instituição que procura transitar da situação de alheamento da realidade social, econômica e política do país à posição de uma instituição central para o desenvolvimento da nação, concentrando seu foco de atenção nas questões políticas.

A Folha de S. Paulo retratou o STF como uma instituição retrógrada, lenta e pouco representativa dos anseios do país. Embora tenha criticado muito o Tribunal, reconheceu nele a potencialidade de tornar-se um ator de grande importância na esfera política. Isso é percebido pelo peso que a variável "papel político" teve no jornal. Já $O$ Estado de S. Paulo divulgou uma imagem mais positiva do STF, identificando nele, em todo o período enfocado, o desempenho de um importante papel político, embora também tenha publicado notícias com declarações de membros do Tribunal procurando modificar a imagem do Supremo, visando a acabar com o distanciamento entre ele e a nação.

GRÁFICO 1-TENDÊNCIA DA VISÃO DO STFNOS JORNAIS FSP EOESP ENTREOS ANOSDE 1979-1988

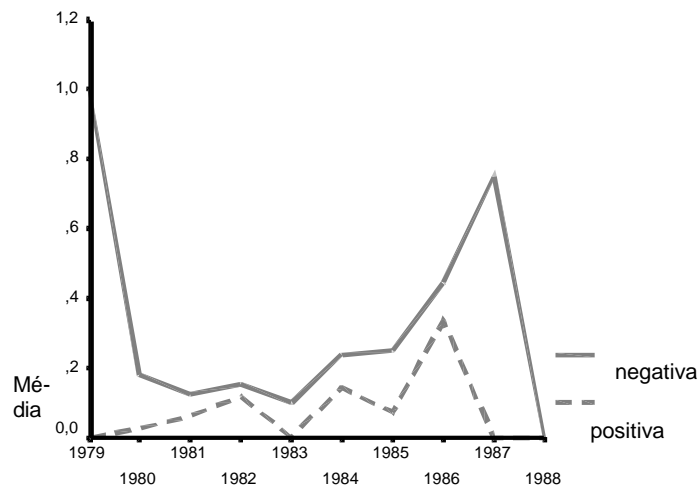

Ano notícia

FONTE: a autora. 
TABELA 1-TENDÊNCIADEAPRESENTAÇÃO DOS INTERESSES CORPORATIVOS DO STF NOS JORNAIS FSP EOESP, NOS ANOS DE 1979-1988 (EM\%)

\begin{tabular}{|l|c|c|c|c|}
\hline \multirow{2}{*}{} & \multicolumn{2}{|c|}{ FSP } & \multicolumn{2}{c|}{ OESP } \\
\cline { 2 - 5 } & $N$ & $\%$ & $N$ & $\%$ \\
\hline Interesses corporativos & 60 & 29,6 & 8 & 25,0 \\
\hline TOTAL & 203 & 100,0 & 32 & 100,0 \\
\hline
\end{tabular}

FONTE: a autora.

O tema "interesses corporativos" é bastante expressivo nos dois jornais, aparecendo um pouco mais na FSP. Nesse período tal variável referiu-se em especial às questões institucionais, como nomeações e posses de novos ministros no STF. Assuntos referentes ao funcionamento do Tribunal foram também bastante expressivos. Notícias tratando de recursos financeiros foram incluídas nessa categoria, mas apareceram pouco. Isso se deve, em grande parte, à necessidade que os ministros tinham de não se referirem a esse assunto, na medida em que tentavam mudar a imagem que os jornais divulgavam de serem membros de uma instituição alheia à realidade do país. Assim, procurando posicionar o Tribunal como uma instituição de essencial importância para a vida política do país, os ministros abordaram pouco a temática financeira.

Um tema de grande importância nesse período foi a crise do poder Judiciário e a necessidade de reformá-lo. O peso dessa variável é maior no jornal OESP do que na FSP; refere-se essencialmente à sobrecarga de trabalho no Tribunal e sua morosidade. Aparece também em meio a notícias que relacionam propostas polêmicas referentes à competência do STF, inspirada no modelo norteamericano, criticando a possível adoção do modelo francês, ou outro modelo europeu, que sugerira a criação de uma Corte Constitucional.

TABELA2-TENDÊNCIADEREFERÊNCIAACRISE/REFORMADOPODERJUDICIÁRIONOSJORNAIS FSP EOESP NOS ANOS DE 1979-1988 (EM\%)

\begin{tabular}{|l|c|c|c|c|}
\hline \multirow{2}{*}{} & \multicolumn{2}{|c|}{ FSP } & \multicolumn{2}{c|}{ OESP } \\
\cline { 2 - 5 } & $N$ & $\%$ & $N$ & $\%$ \\
\hline Crise/reforma do STF & 29 & 14,3 & 8 & 25,0 \\
\hline TOTAL & 203 & 100,0 & 32 & 100,0 \\
\hline
\end{tabular}

FONTE: a autora.

Em reportagem publicada na FSP, em 5.out.1986, Precariedade da Justiça é unanimidade até entre ministros. Nos EUA, debate nacional precede nomeações, são comentados alguns desses aspectos a partir de declarações de alguns ministros. O Ministro Francisco Rezek afirmou que era necessário reformar o poder Judiciário, mas as funções essenciais do STF não deveriam ser mudadas na nova Constituição. Segundo Rezek, essas funções seriam: julgar o Presidente e o vice-Presidente da República, ministros de Estado, parlamentares e magistrados, nos crimes comuns; deliberar sobre litígios entre estados estrangeiros ou organismos internacionais e a União ou Estados; julgar a extradição e conceder habeas corpus quando a pena tiver sido concedida por órgão de sua jurisdição; rever qualquer decisão tomada abaixo dele; declarar a inconstitucionalidade de tratado ou lei federal ou mesmo de atos do governo ou do Congresso Nacional. Nas palavras do Ministro Rezek, "O Brasil adota o modelo americano, que permite ao Judiciário derrubar atos dos governos quando ilegais e medidas do legislativo quando inconstitucionais. Isso representa a 
maior garantia para as pessoas que não dependem de estar politicamente sintonizadas com os ocupantes temporários do governo ou parlamento" (PRECARIEDADE DA JUSTIÇA, 1986). O Ministro declarou ainda que receava a aplicação do modelo francês aqui, como vinha sendo cogitado por alguns. Segundo esse modelo, o poder Judiciário dedica-se apenas a questões penais e demandas entre particulares para resolver interesses privados, não sendo ele um "poder político". Por sua vez, o Ministro Sydney Sanches manifestou opinião de que a justiça deve ser democratizada na base mas elitizada no topo, sendo favorável a que o STF só entrasse em cena quando o interesse nacional estivesse em jogo. Essa elitização dar-se-ia pela aplicação do requisito de relevância. Falou-se ainda da necessidade de adoção dos juizados especiais de pequenas causas, juizados de plantão e outras formas de tomar decisões não recorríveis

Uma segunda parte da reportagem trouxe dados referentes à Suprema Corte dos EUA, indicando que, entre a indicação e a nomeação de um Ministro dessa corte, há um amplo debate nacional. "A devassa na vida pessoal do indicado chega a ser cruel" (ibidem), comentou o Procurador-Geral da República, Sepúlveda Pertence, que, juntamente com o então Ministro da Justiça, Paulo Brossard, era apontado como o nome mais cotado para uma das duas vagas a serem abertas no STF no ano de 1989. Os próprios membros do Tribunal propunham a alteração em alguns critérios da nomeação, como a adoção do requisito de o Ministro nomeado ter menos de 66 anos, "para que sua permanência na corte possa perdurar por quatro anos, no mínimo, a bem da estabilidade jurisprudencial, evitando-se, outrossim, aposentadorias imediatas com pesados ônus para os cofres públicos" (ibidem).

O jornal OESP trouxe notícias comentando o polêmico relatório de Plínio de Arruda sobre a necessidade de reforma do poder Judiciário. Tal relatório dividia-se em três partes: diagnóstico da situação da Justiça; objetivos e pressupostos do anteprojeto de organização do poder Judiciário e do Ministério Público e texto do anteprojeto. O diagnóstico era o de que a Justiça estava demasiado lenta e que essa excessiva demora frusta a reparação dos direitos lesados. Afirma ainda que a Justiça era inacessível aos setores de baixa renda, com os litígios sendo caros e demorados. No que se referia ao STF: ele deveria ser extinto e em seu lugar criada uma Corte Constitucional, com 9 membros, com mandato de 12 anos: 3 seriam escolhidos pelo Supremo Tribunal de Justiça, 3 pelo Congresso Nacional e 3 pelo Presidente da República. A Corte julgaria o Presidente e o vicePresidente da República, os deputados federais, os senadores e o Procurador-Geral da República; julgaria os litígios entre estados estrangeiros ou organismos internacionais e, em caráter constitucional, julgaria a representação por inconstitucionalidade ou para interpretação da lei ou ainda omissão legislativa ou administrativa, inclusive o pedido de medida cautelar.

Ao propor modificações na estrutura do STF, seus ministros afirmaram que "a atual estrutura do STF está correta e não deveria ser mudada. $\mathrm{O}$ que tem que mudar são os mecanismos de declaração de inconstitucionalidade de uma lei". Segundo o Ministro Moreira Alves, a competência para argüição deveria ser ampliada, estendendose do Procurador-Geral aos chefes dos poderes Executivo e Legislativo e aos partidos. Afirmou também que o anteprojeto da Constituição abria demais o acesso de quem poderia representar a inconstitucionalidade de uma lei, prevendo que 11 órgãos políticos - incluindo todos os governadores de estado - poderiam provocar a inconstitucionalidade (PARA MINISTROS DO STF, 1987).

São sempre presentes notícias criticando a "situação jurídica esdrúxula" de a ProcuradoriaGeral ter a prerrogativa de propor a inconstitucionalidade de leis. Diversos setores, inclusive os próprios ministros do Tribunal, reivindicam o direito de a sociedade postular diretamente ao STF.

No que se refere às relações entre os poderes, nota-se que o OESP retratou-as mais que a FSP. Outra diferença está em que a Folha de S. Paulo enfocou mais as tensões com o poder Legislativo, enquanto em $O$ Estado de $S$. Paulo foram as tensões com o poder Executivo que mais apareceram. As relações de apoio não foram abordadas na FSP, tendo uma baixa significância estatística no OESP, aparecendo em apenas 2 das 32 notícias.

Um caso que repercutiu bastante na FSP foi a decisão da Câmara dos Deputados em querer dispensar o STF no julgamento de seus membros. Isso gerou algumas semanas de tensão entre os dois poderes. Tal decisão foi criticada em editoriais 
da FSP (em especial em 11.set.1980), afirmandose a importância de manter o STF como "controlador" das relações entre os poderes, ilustrando o reconhecimento da importância da instituição na arena política.
A relação de tensão com o poder Executivo nessa época, assim como grande parte dessas relações no período seguinte, girou em torno da reforma agrária. O STF opôs-se à sua realização, afirmando que a tradição do direito brasileiro é de proteção à propriedade privada.

TABELA3-TENDÊNCIADOENFOQUEDASRELAÇÕESDE TENSÃO ENTRE STFEPODERES EXECUTIVOE LEGISLATIVO NOSJORNAIS FSP E OESP NOS ANOS DE 1979-1988 (EM\%)

\begin{tabular}{|l|c|c|c|c|}
\hline \multirow{2}{*}{} & \multicolumn{2}{|c|}{ FSP } & \multicolumn{2}{c|}{ OESP } \\
\cline { 2 - 5 } & $N$ & $\%$ & $N$ & $\%$ \\
\hline $\begin{array}{l}\text { Tensão do STF com os poderes } \\
\text { Legislativo ou Executivo }\end{array}$ & 16 & 7,9 & 4 & 12,5 \\
\hline TOTAL & 203 & 100,0 & 32 & 100,0 \\
\hline
\end{tabular}

FONTE: a autora.

As variáveis que indicam o desempenho de um papel político por parte do STF são muito expressivas. Uma notícia publicada pela FSP em 1981 trouxe um pedido dos advogados para que o Tribunal retomasse seu papel político. Isso indica que esse papel deixou de ser desempenhado em algum momento pela instituição, que, no processo de abertura, teria plena condição de retomá-lo. A notícia trouxe também algumas passagens históricas do Tribunal, como a discussão entre os ministros Baleeiro e Gallotti sobre os limites da atuação do STF. “Os advogados estão pedindo ao próprio STF que este retome o seu papel político. E o fazem na hora em que, por coincidência, dois dos seus juízes mais liberais - o ex-advogado Xavier de Albuquerque e o Ministro Leitão de Abreu, de conhecida formação humanística assumem a presidência e a vice-presidência da corte. [...] Mas a primeira afirmação nítida e de repercussão, reclamando o papel político do tribunal, após 1964, partiu do Ministro Aliomar Baleeiro, o ex-parlamentar da UDN e jurista que o marechal Castelo Branco foi buscar na antiga bancada carioca da Câmara Federal para completar a composição então ampliada daquela corte, em 1965. Julgava-se uma representação originária do RJ, sobre questão tributária. Baleeiro sofria objeções dos seus pares a uma tese nova, e o argumento contrário da maioria partia da proibição constitucional, diante da qual seria inviável a inovação proposta pelo Ministro recém-chegado ao Tribunal. Vendo-se já vencido, Baleeiro mudou repentinamente o rumo dos debates e insistiu em que o preceito escrito da Constituição envelhecera. O Supremo, por isso, deveria dar-lhe uma 'interpretação mais consentânea com a realidade atual'. Gallotti, que liderava a reação do plenário à idéia, indagou, em tom de sarcasmo e de desafio, disposto a perturbar a vivacidade do Ministro Baleeiro: 'Vossa excelência quer que os juízes do Supremo mudem a Constituição?' A resposta de Baleeiro veio rápida e também com ironia: 'Quero. Claro que quero. E se não podemos mudá-la, o que é que estamos fazendo aqui nós dois?'. Segundo Baleeiro o STF deveria ser uma "Constituinte permanente". [...] O papel político que os advogados estão cobrando do Supremo é aquela posição eminente no mecanismo do regime, pretendida por Baleeiro e que o atual presidente, Xavier de Albuquerque, disse que o Supremo 'deve ter'” (REIVINDICADO O PAPEL POLÍTICO, 1981).

Em reportagem de 1985 na FSP, o Presidente do Tribunal, Ministro Sydney Sanches, declarou a intenção de o poder Judiciário influir na Constituinte. Defendeu a reforma do poder, desde que assegurada a autonomia administrativa, política e financeira. Defendeu o concurso público para ingresso na magistratura. Atentou para a importância política do Tribunal (judicialização da política) e para o dever que o poder Judiciário tinha de prestar assistência jurídica para a população carente, cuidando também do problema do menor (judicialização das relações sociais). A notícia trouxe ainda declaração do Ministro 
criticando sutilmente os poderes Executivo e Legislativo, afirmando que "o país não carece de melhores leis, mas de poderes mais idôneos e competentes".

TABELA4-TENDÊNCIADEREFERÊNCIAAOPAPELPOLÍTICOEAOPAPELJURÍDICODOSTFNOS JORNAIS FSP EOESP NOS ANOS DE 1979-1988 (EM\%)

\begin{tabular}{|l|c|c|c|c|}
\hline \multirow{2}{*}{} & \multicolumn{2}{|c|}{ FSP } & \multicolumn{2}{c|}{ OESP } \\
\cline { 2 - 5 } & $N$ & $\%$ & $N$ & $\%$ \\
\hline Papel político & 78 & 38,4 & 13 & 40,6 \\
\hline Papel jurídico & 39 & 19,2 & 10 & 31,3 \\
\hline TOTAL & 203 & 100,0 & 32 & 100,0 \\
\hline
\end{tabular}

FONTE: a autora.

Em oposição às notícias que apontavam (ou reivindicavam) desempenho de papel político por parte do STF, havia também a focalização do seu papel jurídico tradicional (geralmente julgamentos de habeas corpus). É perceptível que o OESP dava maior relevância tais questões que a FSP. Comparando a frequiência dessas duas variáveis, "papel político" e "papel jurídico", nota-se que a atribuição do comportamento de um poder político é mais significativa e mais presente que a relação com o desempenho de papéis tradicionais, mesmo no caso da FSP, que transmitia uma visão mais crítica do tribunal.

Os conflitos ideológicos foram um pouco mais enfatizados no jornal FSP, reportando-se sempre ao posicionamento ideológico dos ministros e às divergências internas daí advindas.

TABELA5-TENDÊNCIADOENFOQUEDOSCONFLITOSIDEOLÓGICOSNOSTFNOSJORNAISFSP EOESP NOS ANOSDE 1979-1988 (EM\%)

\begin{tabular}{|l|c|c|c|c|}
\hline \multirow{2}{*}{} & \multicolumn{2}{|c|}{ FSP } & \multicolumn{2}{c|}{ OESP } \\
\cline { 2 - 5 } & $N$ & $\%$ & $N$ & $\%$ \\
\hline Conflitos ideológicos & 19 & 9,4 & 2 & 6,3 \\
\hline TOTAL & 203 & 100,0 & 32 & 100,0 \\
\hline
\end{tabular}

FONTE: a autora.

As relações entre os profissionais do mundo do Direito e o STF apareceram pouco e deveramse sobretudo ao episódio em que o STF decidiu não mais convidar a Ordem dos Advogados do Brasil (OAB) para suas sessões solenes - em virtude de a Ordem não ter enviado representante para a homenagem que o STF prestou ao Ministro Alfredo Buzaid, por ocasião de sua aposentadoria. Dalmo Dallari (autor da notícia publicada em 3.out.1984 - "Advogados comentam decisão do Supremo Tribunal") declarou que o STF confundiu convite com intimação. O Presidente da OAB-SP afirmou que a Ordem não poderia aceitar comparecer a uma sessão em que seria homenageado alguém que participou dos piores momentos de repressão no país. É importante lembrar que Buzaid tentou, enquanto Ministro da Justiça do governo Médici, vincular a entidade ao Ministério do Trabalho, acabando assim com sua autonomia, o que incompatibilizou a OAB com o Ministro.

III.2. Segundo período (1988-1993 FSP - 19881995 OESP)

Nesse segundo período percebe-se um maior reconhecimento, por parte da mídia, da transformação do "perfil" do Tribunal. Os jornais, especialmente a FSP, passaram a retratar a instituição de maneira menos negativa. Após a Constituição de 1988 o STF veio a ocupar um espaço distinto na vida política do país, havendo, em decorrência dessa mudança, uma abertura 
maior para que os ministros se referissem a questões financeiras, por exemplo.

As notícias transpareceram que a atuação do STF modificara-se: ele assumia abertamente sua posição de ator político imprescindível. Essa alteração ficou evidente tanto nas declarações do Ministro Sepúlveda Pertence, de que "Estamos cada vez mais longe da imagem de bons velhinhos do Supremo", e do Ministro Sydney Sanches, de que "o STF não pode deixar de considerar o momento político e econômico por que passa o país na época de seus julgamentos" (RAZÕES POLÍTICAS FAZEM PARTE, 1992), quanto na exacerbação das tensões do Tribunal com os outros poderes constituídos. Essas tensões demarcavam a existência de uma disputa por espaço na tomada de decisões dos rumos políticos do país. Abaixo transcrevemos alguns trechos de notícias que indicam a percepção do STF pelos meios de comunicação nesse período. "Nos últimos 35 dias o país descobriu no STF um alarme capaz de frear um presidente que tem pressa em cumprir as metas de governo e um Congresso mais voltado para o recesso parlamentar que para suas tarefas. [...] O alarme que toca cada vez que um dos poderes desrespeita um dos 315 artigos da Constituição tem servido aos brasileiros como uma aula prática de como devem funcionar o Executivo, o Legislativo e o Judiciário" (STF IMPÕE CONSTITUIÇÃO, 1990). "'Estamos cada vez mais longe da imagem de bons velhinhos do Supremo' (Frase do Ministro Sepúlveda Pertence). O fato de estar julgando ações de inconstitucionalidade movidas por diferentes setores da sociedade faz que os ministros, segundo Pertence, sintam-se mais por dentro do cotidiano do país. O STF já declarou inconstitucional, depois da posse de Collor: a MP n. 190, que suspendia os aumentos salariais em dissídios coletivos; o Decreto n. 99 300, que reduzia os salários dos funcionários públicos em disponibilidade e suspendeu, na última quarta-feira, o recesso dos parlamentares, impedindo a decisão do Senador Nelson Carneiro, de devolver a LDO [Lei de Diretrizes Orçamentárias] ao governo, sem aprovação do Legislativo" (ibidem).

III.3. Terceiro período (1994-1999 FSP - 19961999 OESP)

As notícias desse período confirmam os indícios verificados no momento anterior, de que a partir da Constituição de 1988 o STF teve sua atuação transformada. Note-se que a partir de 1994 o Supremo parece bem menos preocupado com sua imagem pública do que nos anos anteriores. Praticamente não se verificaram notícias em que o STF buscasse pronunciar-se sobre críticas ao seu desempenho, a não ser quando as críticas partem de membros dos outros poderes constituídos. Isso não significa que a opinião pública não tenha exercido influência sobre os atos do Tribunal, mas sim que a instituição alterou a autopercepção de seu papel. Nos anos da abertura sua atuação visava a tornar pública a aproximação com os jornalistas e lutar pela mudança de papel do STF. Agora a luta simbólica era para reafirmar a independência do Tribunal, que já se consolidara um dos poderes da República.

Grande parte das visões negativas sobre o Tribunal devia-se às críticas referentes à sua omissão em manifestar-se sobre alguns casos, atribuindo-se ao STF um comportamento submisso frente aos poderes Executivo e Legislativo.

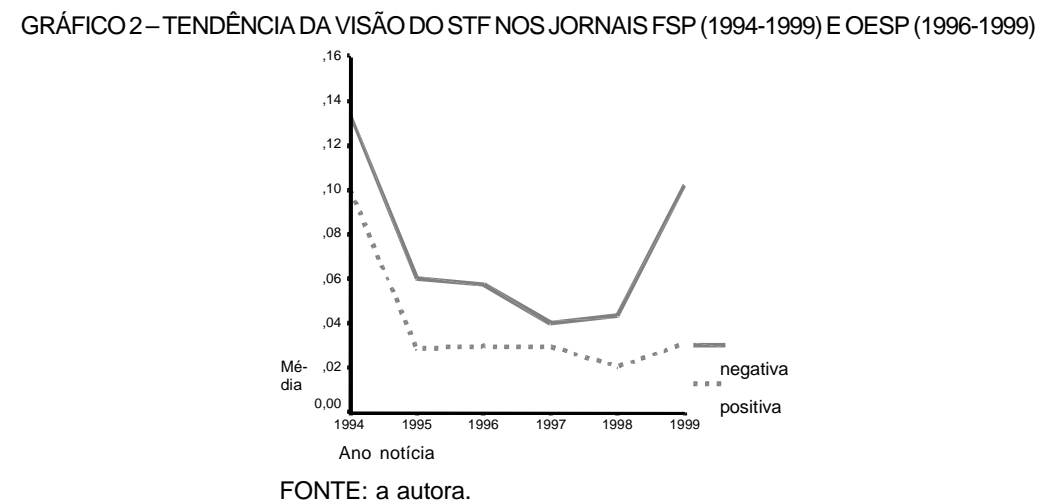

110 
No jornal OESP era freqüente a crítica ao fato de o STF não atuar com todas as ferramentas que a Constituição de 1988 reservou-lhe, como em notícia publicada em 9.jun.1999, em que se acusa o Tribunal de não sanar a deficiência do poder Legislativo, propondo leis ao Congresso Nacional. Ao não o fazer, o Tribunal colocar-se-ia em igualdade de condições com os outros poderes, como omisso. No ano de 1999 praticamente todas as críticas desferidas contra o Tribunal referiramse à sua atuação "independente" no caso da contribuição previdenciária dos servidores públicos inativos (de que trataremos abaixo). Também apareceram críticas relativas às decisões do STF no caso da privatização da Vale do Rio Doce, em que o Tribunal sempre deu vitórias ao governo.

No que se referia às relações com os poderes Executivo e Legislativo, as de apoio e harmonia não são aqui abordadas devido à sua insignificância estatística (verificando um percentual inferior a $0,2 \%$ das notícias); já as relações de tensão são ilustradas na Tabela 6 .

TABELA6-TENDÊNCIADOENFOQUEDASRELAÇÕESDETENSÃOENTRESTFEPODERESEXECUTIVOE LEGISLATIVONOS JORNAIS FSP (1994-1999) E OESP (1996-1999) (EM\%)

\begin{tabular}{|l|c|c|c|c|}
\hline \multirow{2}{*}{} & \multicolumn{2}{|c|}{ FSP } & \multicolumn{2}{c|}{ OESP } \\
\cline { 2 - 5 } & $N$ & $\%$ & $N$ & $\%$ \\
\hline $\begin{array}{l}\text { Tensão entre STF e poderes } \\
\text { Executivo/Legislativo }\end{array}$ & 376 & 7,8 & 267 & 7,6 \\
\hline TOTAL & 4829 & 100,0 & 3514 & 100,0 \\
\hline
\end{tabular}

FONTE: a autora.

Verifica-se que as tensões com o poder Legislativo na maior parte das vezes giraram em torno da interferência do STF na realização das comissões parlamentares de inquérito dos Precatórios, do Narcotráfico e do poder Judiciário. Ocorreram várias discussões e acusações entre os ministros do STF e o então Presidente do Senado, Antônio Carlos Magalhães, com trocas de insultos pessoais e ameaças de retaliação. Inicialmente o Legislativo ameaçava o STF com a reforma do poder Judiciário e a adoção do controle externo. A partir da instauração da CPI do Judiciário, acusava o Tribunal de reagir a essa investigação. Questão levantada por Antônio Carlos Magalhães e que foi classificada algumas vezes na variável "crise/reforma do poder Judiciário" foi a crítica ao processo de nomeação dos ministros, que, empossados em uma determinada gestão, passavam a votar de acordo com os interesses do poder Executivo, ou então a crítica ao fato de alguns dos ministros terem sido nomeados à época do autoritarismo e permanecerem decidindo no período democrático. Outras questões aparecem nessa variável, como a atribuição de culpa ao STF na lentidão da Justiça.
No que se refere às tensões com o poder Executivo foram duas as grandes temáticas desse período: a excessiva edição de medidas provisórias e a cobrança da contribuição previdenciária dos servidores públicos inativos. Em entrevista à FSP, publicada no dia 18.nov.1996, o Ministro Celso de Mello criticou o governo Fernando Henrique Cardoso pelo excessivo apelo às medidas provisórias: "As medidas provisórias são emblemáticas da posição típica de um presidencialismo imperial. Não é correto tornar a Medida Provisória um expediente ordinário de atividade legislativa. Sob esse aspecto, a medida provisória tem um inquestionável componente autoritário. Nada mais é do que a manifestação formal da vontade unilateral do príncipe, vale dizer, do governante. É ele quem, por uma manifestação unilateral de vontade, impõe determinadas prescrições à observância de toda a coletividade. E isso não é aceitável no contexto de uma formação social democrática, especialmente quando o chefe do Executivo é um homem que tem uma formação democrática. Isso me surpreende e me preocupa porque é prática que se tornou crônica na esfera da Presidência da República"(SÁ, 1996). 
O caso da contribuição previdenciária dos servidores públicos inativos e do aumento da alíquota dos funcionários com salários superiores a R\$ 1 200,00, além de envolver a questão da tensão entre o poder Executivo e o STF, apresentou outras variáveis, como "defesa de interesses corporativos". O desenrolar do caso também foi ilustrativo de como a opinião pública tem alguma influência sobre a postura do Tribunal. Esse caso, decidido em outubro de 1999, gerou uma polêmica que esteve presente nos jornais por muito tempo, antes e depois de sua conclusão. Foram inúmeras críticas ao Tribunal, vindas de todos os setores da sociedade e do governo. Um dos aspectos mais criticados foi a declaração do então Presidente da Corte, Ministro Carlos Velloso, de que tal aumento da contribuição seria um confisco, exemplificando-o a partir de sua experiência: com o aumento do desconto, não teria como continuar pagando as prestações de seu carro. O jornal OESP publicou no editorial Não é fácil acabar com isso, do dia 3.out.1999, a seguinte crítica: "É grave. É muito grave. O que o STF está dizendo ao País é que não há problema quando o governo asfixia a sociedade com impostos ou quando corta a cesta básica, desde que o presidente da Corte possa comprar seu carro zero. E desde que uma elite de funcionários tenha seus vencimentos preservados". No dia 5.out.1999 apareceu a seguinte notícia, criticando tal decisão: "O Ministro da Justiça, José Carlos Dias, criticou ontem a decisão do Supremo Tribunal Federal (STF) de suspender a contribuição previdenciária dos servidores inativos e o aumento da alíquota da contribuição dos ativos, dizendo que causou 'dano' e 'prejuízo' à sociedade. 'A decisão tomada pelo Supremo quinta-feira a mim frustrou, a mim desapontou', afirmou. 'Indiscutivelmente, causa um prejuízo grande', acrescentou. 'Quem vai precisar pagar isso é a sociedade, obviamente'" (MARQUES, 1999).

Em nota de resposta às críticas do governo pelas decisões tomadas pela Corte, Velloso afirma que "O Supremo não tem compromissos com projetos governamentais. Seu compromisso é com a Carta. Aliás, projetos governamentais devem ajustar-se à Constituição, não esta àqueles" (O CONSENSO DE BRASÍLIA, 1999).

O jornal OESP trouxe um editorial comentando artigo publicado na revista semanal inglesa The
Economist, em que a decisão do STF é criticada. Como transcreve o jornal, a revista afirma que a sentença do Supremo “'Desferiu um golpe não apenas na austeridade fiscal, mas também na justiça social' e se explica antes pela 'rapacidade do corporativismo' do que pelo 'zelo constitucional ou independência judicial"' (UM LOUCO QUE RASGA, 1999).

Em meio a tantas críticas, o Presidente do STF alterou o tom do seu discurso, sem, no entanto, voltar atrás em sua decisão. "O presidente do Supremo Tribunal Federal (STF), Carlos Velloso, declarou ontem que se o governo alterar a Constituição, será possível instituir a contribuição previdenciária dos servidores públicos aposentados e desvincular o ganho dos funcionários que estão na ativa do benefício dos inativos. 'Digo isso em tese', afirmou, ressaltando que a questão tem de ser muito bem analisada sob todos aspectos jurídicos e as alterações não podem atingir as cláusulas pétreas dos direitos e garantias individuais. [...] Indagado se o STF não poderia ser flexível nesta questão das contribuições para salvar a Previdência e os Estados, Velloso foi enfático. 'O Supremo nunca pode ser maleável em termos de Constituição porque hoje é uma causa nobre, mas amanhã pode ser por uma causa menos nobre; o Supremo jamais abriria mão de cumprir a Constituição"” (MONTEIRO, 1999).

Esse caso também gerou tensões com o poder Legislativo, especialmente entre os presidentes do Senado e do STF. Antonio Carlos Magalhães, além de criticar a decisão do Tribunal, criticou os ministros por estes participarem demais do debate público, lamentando a existência no país de "ministros que estão todos os dias na imprensa, falando o que não devem". Segundo ele, essa atitude "vulgariza o papel do Judiciário" (COSTA, 1999).

Uma variável que diretamente relacionada às tensões com o governo é "crise/reforma do poder Judiciário". Nota-se que essas duas variáveis comportaram-se de maneira semelhante a partir de 1996, indicando que quanto maior a tensão com o governo, maior a incidência da afirmação da necessidade de reformar o poder Judiciário - em especial, alterar a atribuição de poderes e o funcionamento do STF, na maioria das vezes apontando para a necessidade de adoção do controle externo. Comparada ao período de 1979- 
1988, em que havia a preocupação em discutir as alterações que o STF deveria sofrer em virtude da
Constituinte, a incidência dessa variável diminuiu, mas ainda assim teve um peso considerável.

TABELA7-TENDÊNCIADAREFERÊNCIAÀCRISE/REFORMADOPODERJUDICIÁRIO, NOSJORNAIS
\begin{tabular}{|l|c|c|c|c|}
\hline \multirow{2}{*}{ FSP (1994-1999) E OESP (1996-1999) (EM \%) } \\
\cline { 2 - 5 } & \multicolumn{2}{|c|}{ FSP } & \multicolumn{2}{c|}{ OESP } \\
\cline { 2 - 5 } & $N$ & $\%$ & $N$ & $\%$ \\
\hline Crise/reforma do STF & 359 & 7,4 & 322 & 9,2 \\
\hline TOTAL & 4829 & 100,0 & 3514 & 100,0 \\
\hline
\end{tabular}

FONTE: a autora.

O Ministro Sepúlveda Pertence, em uma entrevista dada ao jornal FSP em 1995, quando assumiu a Presidência da instituição, fez a seguinte afirmação: "Essa história de controle externo só vem à tona, não a propósito de uma reflexão séria sobre os problemas do Judiciário, mas sempre depois de uma decisão polêmica dos tribunais, particularmente do Supremo. O que dá para desconfiar. Apesar da desculpa óbvia de que não se pretende controlar as decisões do Judiciário, no dia em que houvesse um órgão controlador externo, seria sobre ele que recairiam as críticas que hoje se fazem à Justiça. No ano passado, por exemplo, o Supremo foi chamado de demagógico e populista por um político conservador (Pertence não quis citar o nome). Poucos meses depois, um político de esquerda protestou contra uma decisão chamando-a de reacionária e antipopular. Curiosamente, os dois concluíam que era necessário o controle externo do Judiciário. Volto a insistir: dá para desconfiar dessa intenção" (NOVO PRESIDENTE DO SUPREMO, 1995).

Além do controle externo, há referência a temas "tradicionais" quando o assunto é a crise da justiça: morosidade, falta de recursos materiais e humanos, excesso de trabalho. Junto a esses problemas algumas soluções são apontadas, como a adoção da súmula vinculante e do incidente de constitucionalidade. Esses temas, por serem polêmicos, não encontram unanimidade entre os ministros, menos ainda nas opiniões publicadas nos jornais. Dos onze ministros do STF, apenas Celso de Mello, Maurício Corrêa e Marco Aurélio de Mello declararam-se contrários ao efeito vinculante.

No que se refere aos interesses corporativos, nota-se que, embora sua freqüência tenha diminuído nesse período, comparada a 1979-1988, essa variável teve ainda um peso bastante significativo. Seu conteúdo também alterou-se. Ela refere-se muito à participação dos ministros em cerimônias promovidas pelo governo e mais ainda às questões financeiras. Foi também bastante significativa a reivindicação dos ministros e de setores da opinião pública para a nomeação de uma mulher ao STF.

TABELA8-TENDÊNCIADEAPRESENTAÇÃO DE INTERESSES CORPORATIVOS DO STF, NOS JORNAIS FSP (1994-1999) E OESP (1996-1999) (EM \%)

\begin{tabular}{|l|c|c|c|c|}
\hline \multirow{2}{*}{} & \multicolumn{2}{|c|}{ FSP } & \multicolumn{2}{c|}{ OESP } \\
\cline { 2 - 5 } & $N$ & $\%$ & $N$ & $\%$ \\
\hline Interesses corporativos & 918 & 19,0 & 709 & 20,2 \\
\hline TOTAL & 4829 & 100,0 & 3514 & 100,0 \\
\hline
\end{tabular}

FONTE: a autora. 
TABELA9-TENDÊNCIADOENFOQUEDOSCONFLITOSIDEOLÓGICOSNOSTF,NOSJORNAISFSP (1994-1999) E OESP (1996-1999) (EM \%)

\begin{tabular}{|l|c|c|c|c|}
\hline \multirow{2}{*}{} & \multicolumn{2}{|c|}{ FSP } & \multicolumn{2}{c|}{ OESP } \\
\cline { 2 - 5 } & $N$ & $\%$ & $N$ & $\%$ \\
\hline Conflitos ideológicos & 236 & 5,0 & 147 & 4,2 \\
\hline TOTAL & 4829 & 100,0 & 3514 & 100,0 \\
\hline
\end{tabular}

FONTE: a autora.

A incidência dos conflitos ideológicos também diminuiu se comparada ao período 1979-1988. No que se refere ao conteúdo dessa variável ocorreu uma certa modificação: embora continuasse tratando da postura ideológica dos ministros e dos desentendimentos que elas provocavam, as disputas passaram a ser mais diretas, sobretudo nas questões corporativas - pois os ministros passaram a comportar-se como membros de um poder político, assumindo um perfil menos formal e mais ativo.

A referência ao papel jurídico tradicional diminuiu consideravelmente se comparada aos anos 1979-1988 e, assim como nesse período, nos anos de 1996-1999 o jornal OESP tendeu a retratar mais tal questão que a FSP. O seu conteúdo diz respeito, sobretudo, aos julgamentos de habeas corpus muito freqüentes nesses anos em decorrência das comissões parlamentares de inquérito -, julgamentos de pedidos de extradição, decisão de conflitos entre estados e União (no caso de dívidas e moratórias) e também à posição do STF como última instância recursal do poder Judiciário.

Já em relação à variável "papel político", notase que sua frequiência cresceu bastante confrontada com a período de 1979-1988. Isso se deveu principalmente aos efeitos provocados pela Constituição de 1988, que, como dito, ampliou a esfera de atuação do Tribunal e, mais ainda, ampliou os agentes legitimados a propor a Ação Direta de Inconstitucionalidade (ADIN), o que aumentou consideravelmente a entrada de ações no STF.

Os principais temas propulsores da referência ao papel político foram o elevado número de ADINs (como nos casos da privatização da Companhia Vale do Rio Doce, da constitucionalidade da Contribuição Provisória sobre Movimentações Financeiras, do aumento da contribuição previdenciária e da inclusão dos servidores públicos inativos nessa contribuição) e o perfil de atores políticos que os ministros do STF passaram a assumir.

A elevada frequiência dessa variável - mais de $50 \%$ das notícias sobre o STF nos dois jornais revela que o STF passou a ser identificado como um poder político de fato, tendo grande importância na vida política do país. Esses aspectos já foram evidenciados no segundo período analisado. O discurso do Ministro Pertence foi ilustrativo desse novo perfil de Ministro; ele ainda revelou que o "mito do formalismo técnico-jurídico" é uma das principais causas da crise da Justiça: "A mentira técnicojurídica que, nas últimas décadas, pretendeu moldar o desempenho de juízes e advogados. Mentira sedutora, pois transformava os juízes em descobridores exclusivos 'do único sentido válido de um fato'. [...] Mais do que independentes, os juízes ficaram inatingíveis, longe de erro e correção, sentenças que se pretendiam extraterrestres. Mas vem agora Pertence, com modéstia mineira e autoridade tríplice de líder de advogados, procuradores e juízes, e diz: 'Somos brasileiros de classe média, em determinado tempo e situação. É inequívoco que todo esse condicionamento, no tempo e no espaço, influi muitas vezes até inconscientemente'. E abre portas para uma doutrina jurídica mais realista e democrática" (FALCÃO, 1995). 
TABELA10-TENDÊNCIADEREFERÊNCIAAOPAPELPOLITICOEAOPAPELJURÍDICODOSTFNOS JORNAIS FSP (1994-1999) E OESP (1996-1999)

\begin{tabular}{|l|c|c|c|c|}
\hline \multirow{2}{*}{} & \multicolumn{2}{|c|}{ FSP } & \multicolumn{2}{c|}{ OESP } \\
\cline { 2 - 5 } & $N$ & $\%$ & $N$ & $\%$ \\
\hline Papel político & 2609 & 54,0 & 1789 & 51,0 \\
\hline Papel jurídico & 812 & 16,8 & 946 & 27,0 \\
\hline TOTAL & 4829 & 100,0 & 3514 & 100,0 \\
\hline
\end{tabular}

FONTE: a autora.

A judicialização das relações sociais foi pouco abordada, referindo-se quase sempre à necessidade de democratização da justiça através da instalação dos juizados especiais e da redução de custos da justiça, ampliando o acesso da população ao poder Judiciário (o que aparece na maioria das vezes relacionado a notícias enfocando a reforma do poder Judiciário). Outro tema focalizado foi a violência e a criminalidade, e o papel que o STF, e o Judiciário como um todo, teria a cumprir para encontrar soluções para esses problemas.

A referência à politização da justiça também foi rara, verificando maior frequiência no período pré-eleições presidenciais, em 1997-1998, quando o Ministro Sepúlveda Pertence era cotado como um possível candidato ao Planalto. Também apareceu em momentos de decisões polêmicas do Tribunal, em que setores da sociedade e do governo (geralmente os "perdedores") classificaram essas decisões como políticas, afirmando que a lógica político-partidária invadia cada vez mais um tribunal que deveria ter uma orientação "técnico-formal". Assim, na maior parte das vezes em que apareceu o argumento da politização da justiça, ele teve uma conotação negativa. É interessante notar que outras vezes aparece argumento absolutamente contrário, afirmando a necessidade de haver uma politização maior das decisões, criticando o formalismo. "O julgamento do Supremo, argutamente analisado nos editoriais 'O Consenso de Brasília', do Estado [de São Paulo], e 'Do que vamos morrer', do Jornal da Tarde, desnuda as dramáticas consequiências que podem advir do formalismo técnico que tem dominado amplos setores do Judiciário. Apoiados em princípios jurídicos verdadeiros e nas melhores intenções, alguns magistrados estão perdendo conexão com a vida real. O respeito à Constituição é um pré-requisito da democracia, mas a interpretação da norma constitucional é condição indispensável para a realização da justiça. Parece-me que essa visão, essencial para a segurança de um vôo submetido a forte turbulência (o Brasil não resistirá aos sucessivos atrasos na implantação do ajuste fiscal), faltou aos ministros do Supremo Tribunal Federal. A prova está na nota à imprensa distribuída pelo presidente do STF, Ministro Carlos Velloso. Em resposta às críticas do governo pelas decisões tomadas pela Corte, Velloso afirma que o Supremo 'não tem compromissos com projetos governamentais. Seu compromisso é com a Carta'. E concluiu: 'Aliás, projetos governamentais devem ajustar-se à Constituição, não esta àqueles' . A declaração, embora formalmente correta, evidencia uma notável dificuldade para captar a gravidade da situação brasileira. $\mathrm{O}$ apego à letra da lei está bloqueando o fluxo de oxigênio que pode salvar o paciente" (FORMALISMO QUE MATA, 1999).

Essas diferentes visões em relação ao envolvimento do Judiciário com a política indicam a existência de uma disputa pelo conteúdo da ideologia profissional dominante.

\section{CONCLUSÕES}

Nesta pesquisa buscou-se perceber a imagem e a atuação do STF no processo de redemocratização, por meio de veículos de formação da opinião pública. Não foram discutidas questões da implicação do relacionamento do STF com os meios de comunicação; estes serviram apenas como um "termômetro" da inserção e atuação desse ator no cenário público nacional. A conclusão a que se pôde chegar foi a de que o Tribunal 
buscou, no primeiro momento (1979-1988), transformar a imagem de que aparentemente desfrutava na opinião pública, passando de uma situação em que era identificado como alheio à realidade e às necessidades do país, à imagem de instituição de importância central para o desenvolvimento da nação. Discurso muito enfático entre os ministros nessa época é o de que o Tribunal precisava aproximar-se da opinião pública; entre os demais setores que se fizeram representar nos jornais, o discurso era o de reivindicação para que o STF voltasse a exercer seu papel político. A análise das notícias possibilita a inferência de que, no momento em que o regime ditatorial acirrou-se, o STF deixou a cena pública e que, quando se iniciou a abertura política, o Tribunal voltou a manifestar-se e a buscar novamente seu espaço entre os poderes políticos.

Essa busca do STF por modificar suas atuação e imagem coincidiu com as alterações em suas atribuições constitucionais. Como dito, essas tranformações foram mais expressivas no momento seguinte, posterior à Constituição de 1988, quando a opinião pública reconheceu efetivamente a mudança de perfil do Supremo. A partir de então ele passa a ser identificado como um poder forte e autônomo. Por ser reconhecido dessa maneira por setores da opinião pública, por ter conquistado um grande espaço na mídia, as críticas a ele aumentaram, assim como as tensões e disputas com os outros dois poderes do Estado. Aumentou também a veiculação pelos meios de comunicação de reivindicações corporativas dos ministros e de notícias referentes ao funcionamento do Tribunal.

Na imagem que os meios de comunicação veicularam do Tribunal e de seus ministros predominaram as questões políticas, não sendo muito enfatizada a relação do STF com questões sociais. Ele foi identificado como um ator essencialmente político. Quando o assunto em pauta era a transformação do STF em Corte Constitucional, percebeu-se que, apesar dos conflitos ideológicos verificados entre os ministros, foi estabelecido uma espécie de consenso, pois a sobrevivência do Tribunal como poder estava em sua sobrevivência como cúpula do poder Judiciário.

Com base na análise das notícias e considerando as limitações que os intrumentais de pesquisa aqui utilizados colocaram, é possível inferir que o STF tornou-se um ator de suma importância no processo de redemocratização e consolidação da democracia no Brasil, sendo que essa postura teve apoio na identidade profissional dos ministros e em seus conhecimentos técnicos para diferenciar-se dos outros poderes políticos.

Assim, o apelo à autoridade do conhecimento jurídico como distinção não vem em oposição à política, mas sim em complementação. Os ministros não negam o papel político que podem, devem e buscam exercer, e, sim, procuram diferenciá-lo a partir dos valores da imparcialidade, da transparência e da segurança jurídica. Com isso visam a desempenhar um papel de importância no cenário político, oferencendo valores que os políticos convencionais não podem fornecer.

Fabiana Luci de Oliveira (fabiana_luci@yahoo.com.br)é Doutoranda em Ciências Sociais pela Universidade Federal de São Carlos (UFSCar) e bolsista da Fundação de Amparo à Pesquisa do Estado de São Paulo (FAPESP).

\section{REFERÊNCIAS BIBLIOGRÁFICAS}

AQUINO, M. A. 1999. Censura, imprensa e Estado autoritário (1968-1978). O exercício cotidiano da dominação e da resistência : O Estado de $S$. Paulo e o Movimento. Bauru : USC.

ARANTES, R. B. 1997. Judiciário e política no Brasil. São Paulo : Sumaré.
ARANTES, R. B. \& KERCHE, F. 1999. Judiciário e democracia no Brasil. Novos Estudos CEBRAP, São Paulo, n. 54, p. 2742 , jul.

BALEEIRO, A. 1967. O Supremo Tribunal Federal, esse outro desconhecido. Rio de Janeiro : Forense. 
BONELLI, M. G. 2002. Profissões, política e Estado. São Carlos : UFSCAR.

CAPElato, M. H. \& MOTA, C. G. 1981. História da Folha de São Paulo (1921-1981). São Paulo : Impress.

CAPELATO, M. H. \& PRADO, M. L. 1980. O bravo matutino, imprensa e ideologia : o jornal O Estado de S. Paulo. São Paulo : Alfaômega.

CASTRO, M. F. 1997. O Supremo Tribunal Federal e a judicialização da política. Revista Brasileira de Ciências Sociais, São Paulo, v. 12, n. 34, p. 147-155.

COSTA, E. V. 2001. O Supremo Tribunal Federal e a construção da cidadania no Brasil. São Paulo : Instituto de Estudos Jurídicos e Econômicos.

COSTA, R. 1999. ACM volta a atacar Velloso e decisão do STF. Folha de S. Paulo, 28.out.

FALCÃO, J. 1995. O Supremo e a mentira. Folha de S. Paulo, 23.jun.

FERREIRA FILHO, M. G. 1994. poder Judiciário na Constituição de 1988 : judicialização da política e politização da justiça. Revista de Direito Administrativo, São Paulo, v. 198, p. 1-17. out.-dez.

FREIDSON, E. 2001. Professionalism - The Third Logic. Cambridge : Polity.

GARAPON, A. 1999. O juiz e a democracia : o guardião das promessas. Rio de Janeiro : Revan.

HABERMAS, J. 1997. Direito e democracia. Entre facticidade e validade. V. I. Rio de Janeiro : Tempo Brasileiro.

KOERNER, A. 1999. O debate sobre a reforma judiciária. Novos Estudos CEBRAP, São Paulo, n. 54, p. 11-26, jul.

MACEDO, R. P. \& MARTES, A. C. B. 2000. A reforma do Judiciário e suas propostas. Artigo apresentado no XXIV Encontro da
Associação Nacional de Pesquisa e Pósgraduação em Ciências Sociais, realizado em Petrópolis (RJ), de 23 a 27.out.2000. Digit.

MARQUES, H. 1999. Dias lamenta decisão e diz que sociedade pagará por prejuízo, Hugo Marques. O Estado de S. Paulo, 5.out.

MONTEIRO, T. 1999. Só alteração na Carta permite taxação, diz Velloso. $O$ Estado de S. Paulo, 16.out.

OLIVEIRA, F. L. 2002. A identidade profissional dos ministros do STF no processo de redemocratização do Brasil. Artigo apresentado no XXVI Encontro da Associação Nacional de Pesquisa e Pós-graduação em Ciências Sociais, realizado em Caxambu (MG), de 22 a 26.out.2002. Digit.

OSIEL, M. J. 1995. Diologue with Dictators : Judicial Resistance in Argentina and Brazil. Law and Social Inquiry, Chicago, v. 20, n. 2, p. 481-560, Winter.

RODRIGUES, L. B. 1965-1991. História do Supremo Tribunal Federal. 3 Tomos. Rio de Janeiro : Civilização Brasileira.

ROSA, F. A. M. 1985. Brasil. Os anos de autoritarismo : justiça e autoritarismo. Rio de Janeiro : J. Zahar.

SÁ, N. 1996. Ministro do STF quer uma mulher na Suprema Corte. Folha de S. Paulo, 18.nov.

VALE, O. T. 1976. O Supremo Tribunal Federal e a instabilidade político-institucional. Rio de Janeiro : Civilização Brasileira.

VIEIRA, O. V. 1993. O Supremo Tribunal Federal e a consolidação da democracia : 1988 a 1993. São Paulo. Dissertação (Mestrado em Ciência Política). Universidade de São Paulo.

WERNECK VIANNA, L., CARVALHO, M. A. R., MELO, M. P. C. \& BURGOS, M. B. 1999. A judicialização da política e das relações sociais no Brasil. Rio de Janeiro: Revan. 


\section{OUTRAS FONTES}

Espectador Supremo. 1980. Folha de S. Paulo, 1.nov.

Reivindicado o papel político do Supremo. 1981. $O$ Estado de S. Paulo, 15.mar.

Revalorizar a Justiça, proposta do Supremo. 1982. Folha de S. Paulo, 14.abr.

Advogados comentam decisão do Supremo Tribunal. 1984. Folha de S.Paulo, 3.out.

Precariedade da Justiça é unanimidade até entre ministros. Nos EUA, debate nacional precede nomeações. 1986. Folha de S. Paulo, 5.out.

Para ministros do STF, mecanismos de controle devem sofrer mudanças. 1987. Folha de S. Paulo, 10.jul.

STF impõe Constituição e muda imagem. 1990. O Estado de S. Paulo, 8.jul.
Razões políticas fazem parte do STF. Ministros que poderão vir a julgar Collor nem sempre se limitam aos aspectos técnicos. 1992. $O$ Estado de S. Paulo, 30.ago.

Novo Presidente do Supremo diz que faltam juiz e dinheiro. 1995. Folha de S. Paulo, 14.maio.

Não é fácil acabar com isso. 1999. O Estado de S. Paulo, 3.out., Editorial.

O Consenso de Brasília. 1999. O Estado de S. Paulo, 5.out., Editorial.

Formalismo que mata. 1999. O Estado de S. Paulo, 11.out.

Um louco que rasga dinheiro. 1999. O Estado de S. Paulo, 17.out., Editorial. 